\title{
LYTAK1, a TAK1 inhibitor, suppresses proliferation and epithelial-mesenchymal transition in retinal pigment epithelium cells
}

\author{
ZHEN CHEN ${ }^{1-3}$, YAN MEI $^{2}$, HUO LEI $^{2}$, RUN TIAN $^{2}$, NINGHUA NI $^{2}$, \\ FANG HAN ${ }^{2}$, SHENGWEI GAN ${ }^{1}$ and SHANQUAN SUN ${ }^{1}$ \\ ${ }^{1}$ Department of Cell Engineering and Biological Engineering, Chongqing Medical University, \\ Chongqing 400016; ${ }^{2}$ Department of Ophthalmology; ${ }^{3}$ Research Center of Fundus Disease, \\ The First People's Hospital of Yunnan, Kunming, Yunnan 650032, P.R. China
}

Received June 2, 2015; Accepted April 21, 2016

DOI: $10.3892 / \mathrm{mmr} .2016 .5275$

\begin{abstract}
The proliferation of retinal pigment epithelium (RPE) cells following epithelial-mesenchymal transition (EMT) is critical in proliferative vitreoretinopathy (PVR), which results in retinal detachment and the loss of vision. The current study was conducted to examine the importance of transforming growth factor $\beta-1$ (TGF- $\beta 1$ )-activated kinase 1 (TAK1) inhibitor (LYTAK1) in regulating EMT and the proliferation of RPE cells. RPE cells were pre-treated with increasing concentrations of LYTAK1 prior to treatment with TGF- $\beta 1$ for $24 \mathrm{~h}$. The effect of LYTAK1 on RPE cell proliferation was examined using a Cell Counting kit-8 assay. The expression levels of TAK1, smooth muscle actin, fibronectin, p-Smad2, p-Smad3, nuclear factor (NF)-кB p65 and IкB kinase $\alpha$ were detected by western blotting. LYTAK1 suppressed the proliferation and migration of RPE cells. Additionally, LYTAK1 significantly prevented TGF- $\beta 1$-induced EMT by decreasing the levels of fibronectin and $\alpha$-smooth muscle actin. It was demonstrated that the effects of LYTAK1 were via the Smad signaling pathway. The present study also determined, that the underlying mechanism of the effects of LYTAK1 on EMT in $\mathrm{RPE}$ cells involves downregulation of the NF- $\mathrm{KB}$ signaling pathway. In conclusion, TAK1 transcription factor was shown to be important in TGF- $\beta 1$-induced EMT in human RPE cells. Thus, the results of this study aid in elucidating the pathogenesis of human PVR. In addition, this study suggests that specific inhibition by LYTAK1 may provide a novel approach for the treatment and prevention of PVR.
\end{abstract}

Correspondence to: Dr Shanquan Sun, Department of Cell Engineering and Biological Engineering, Chongqing Medical University, 1 Medical School Road, Chongqing 400016, P.R. China E-mail: sun_shanquanc@163.com

Key words: LYTAK1, proliferation, retinal pigment epithelium cells, epithelial-mesenchymal transition

\section{Introduction}

Retinal pigment epithelial (RPE) cells are important for maintaining the function of the visual system. Normal RPE cells are quiescent and do not proliferate or migrate $(1,2)$. Epithelial-mesenchymal transition (EMT), proliferation, invasion and migration of RPE cells are key in the development of proliferative vitreoretinopathy (PVR) and various other fibroproliferative eye diseases, which lead to blindness. The proliferation, directional migration to the vitreous and EMT of quiescent, differentiated RPE cells contribute to the development of PVR. During PVR, RPE cells transform into fibroblast-like cells through EMT (3). EMT may be triggered by various signaling molecules, including epidermal growth factor and fibroblast growth factor (FGF); however, transforming growth factor $\beta-1$ (TGF- $\beta 1$ ) is considered to be the primary regulator of EMT $(4,5)$.

TGF- $\beta$-induced EMT is known to promote cell migration and invasion. Lens epithelial cells and corneal epithelial cells have been shown to undergo TGF- $\beta$-mediated EMT (6). TGF- $\beta$ is a multifunctional cytokine that is involved in number of biological functions, including cell growth, differentiation, immunomodulation, oxidative stress and endoplasmic reticulum (ER) stress $(7,8)$. TGF- $\beta$ also contributes to pericellular proteolysis via regulation of the expression and secretion of plasminogen activators. TGF- $\beta$ promotes EMT via the Smad and non-Smad signaling pathways, and crosstalks between them. TGF- $\beta 1$ activates Smad-independent pathways, including ERK, p38 mitogen-activated protein kinase (MAPK), c-Jun N-terminal kinases (JNK), phosphatidylinositol 3-kinase/Akt and nuclear factor $\kappa \mathrm{B}(\mathrm{NF}-\kappa \mathrm{B})(9)$.

TGF- $\beta$-activated kinase 1 (TAK1) is a serine/threonine kinase and is a member of the MAPK kinase kinase family (10). TAK1 is an important regulator of the cell cycle and apoptosis, and its activity is regulated by various cytokines, including interleukin-1 and TGF- $\beta$ (10). Once activated, TAK1 in turn activates intracellular kinases, including p38 MAPK, JNK, and the I- $\kappa B$ kinase complex (11). Activated TAK1 then transduces signals to several downstream signaling cascades, 
including the MKK4/7-JNK, MKK3/6-p38 MAPK, and $\mathrm{NF}-\kappa \mathrm{B}$-inducing kinase-I $\kappa \mathrm{B}$ kinase (IKK) (12).

To the best of our knowledge, the present study was the first to identify TAK1 upregulation in human RPE cells with TGF- $\beta 1$-induced EMT. Inhibition of TAK1 activity by LYTAK1 significantly inhibited the proliferation of RPE cells. Additionally, LYTAK1 significantly prevented TGF- $\beta 1$-induced EMT via the regulation of the canonical Smad signaling pathway. The current study also demonstrated that the $\mathrm{NF}-\kappa \mathrm{B}$ signaling pathway is affected by LYTAK1 during EMT. Therefore, the results of the present study suggest that inhibition of TAK1 activity may be a novel approach for the treatment and prevention of PVR.

\section{Materials and methods}

Cell culture and treatment groups. The ARPE-19 human RPE cell line was provided by Professor Fu Shang at the Laboratory for Nutrition and Vision Research, Tufts University (Boston, MA, USA), and cultured in Dulbecco's modified Eagle's medium (Invitrogen; Thermo Fisher Scientific, Inc., Waltham, MA, USA) containing $10 \%$ fetal bovine serum (Gibco; Thermo Fisher Scientific, Inc.). The cells were grown to $70 \%$ confluence at $37^{\circ} \mathrm{C}$ in a humidified atmosphere containing $5 \% \mathrm{CO}_{2}$ and were dissociated with a $0.25 \%$ trypsin- $0.02 \%$ ethylenediaminetetraacetic acid solution (Sigma-Aldrich, St. Louis, MO, USA). TGF- $\beta 1$ and LYTAK1 were purchased from Sigma-Aldrich.

The cells were randomly divided into 6 groups: Control group, TGF- $\beta 1$ group, TGF- $\beta 1+$ LYTAK1 $(1 \mu \mathrm{M})$ group, TGF- $\beta 1+$ LYTAK1 $(10 \mu \mathrm{M})$ group, TGF- $\beta 1+$ LYTAK1 $(25 \mu \mathrm{M})$ group and TGF- $\beta 1+$ LYTAK1 $(50 \mu \mathrm{M})$ group.

RNA isolation and reverse transcription-quantitative polymerase chain reaction $(R T-q P C R)$. Total RNA was extracted from cells using TRIzol reagent (Invitrogen; Thermo Fisher Scientific, Inc.) according to the manufacturer's protocol. cDNA was synthesized using a reverse transcription kit (Takara Biotechnology Co., Ltd., Siga, Japan), using protocols recommended by the manufacturer. For quantitative analysis of mRNA expression levels, SYBR PrimeScript RT-PCR kit (Takara Biotechnology Co., Ltd.) was used to amplify the target genes with the ABI Prism 7000 sequence detection system (Applied Biosystems; Thermo Fisher Scientific, Inc.). PCR primers were as follows: TAK1, forward 5'-GAATTAGCGCTTTGGGTT GC-3' and reverse 5'-TTTCTTTCGCAGTGCTGCAT-3'; $\alpha$-SMA, forward 5'-CTATTCCTTCGTGACTACT-3' and reverse 5'-ATGCTGTTATAGGTGGTGGTT-3'; fibronectin, forward 5'-TCTCCTGCCTGGTACAGA ATATGTAGT GAG-3' and reverse 5'-GGTCGCAGCAACAACTTCCAG GT-3'; and GAPDH, forward 5'-GGCAAATTCAACGGC ACAGTC-3' and reverse 5'-GCTGACAATCTTGAGTGA GTT-3'. The PCR procedure was as follows: $94^{\circ} \mathrm{C}$ for $4 \mathrm{~min}$; $94^{\circ} \mathrm{C}$ for $20 \mathrm{sec}, 55^{\circ} \mathrm{C}$ for $30 \mathrm{sec}$ and $72^{\circ} \mathrm{C}$ for $20 \mathrm{sec} ; 2 \mathrm{sec}$ for plate reading for 40 cycles; and melt curve from $65-95^{\circ} \mathrm{C}$. Relative quantification of gene expression was performed using the $2^{-\Delta \Delta \mathrm{Cq}}$ method (13). Glyceraldehyde 3-phosphate dehydrogenase (GAPDH) mRNA was used as an internal control.
Western blot analysis. For total protein extraction, cells were lysed with $100 \mu 1$ radioimmunoprecipitation assay lysis buffer with protease inhibitor cocktail (Invitrogen; Thermo Fisher Scientific, Inc.). The cell lysates were collected following centrifugation $(6,000 \mathrm{x} \mathrm{g}$ for $10 \mathrm{~min})$ and mixed with $5 \mathrm{X}$ sodium dodecyl sulfate (SDS) sample buffer (Takara Biotechnology, Inc., Dalian, China), and a bicinchoninic acid assay was used to measure the protein levels. The samples $(40 \mu \mathrm{g})$ were loaded and separated on $10 \%$ SDS-PAGE (Takara Biotechnology, Inc.), and then transferred to polyvinylidene fluoride membranes (EMD Millipore, Billerica, MA, USA). The membranes were blocked in 5\% non-fat milk and incubated with the following primary antibodies at $4^{\circ} \mathrm{C}$ overnight: anti-TAK1 (1:2,000; sc-7967), anti- $\alpha$-smooth muscle actin (SMA; 1:1,500; sc-53015), anti-fibronectin (1:2,000; sc-81769), anti-NF- $\mathrm{B}$ p65 (1:2,000; sc-8008), anti-IKK $\alpha$ (1:2,000; sc-7606), anti-p-Smad2 (1:2,000; sc-101801), anti-p-Smad3 $(1: 2,000 ;$ sc-130218) and GAPDH $(1: 1,500 ;$ sc-166574; all from Santa Cruz Biotechnology, Inc., Dallas, TX, USA). After washing with phosphate-buffered saline with Tween-20, the membranes were incubated with goat anti-mouse IgG horseradish peroxidase-conjugated secondary antibodies $(1: 3,000$; sc-395760; Santa Cruz Biotechnology, Inc.) and goat anti-rabbit HRP-conjugated secondary antibodies (1:2,000; sc-2030; Santa Cruz Biotechnology, Inc.) for $1 \mathrm{~h}$ at room temperature. The bands on the membranes were visualized using chemiluminescence detection reagents (Roche Diagnostics $\mathrm{GmbH}$, Mannheim, Germany). Densitometic analysis was conducted using Image J version 1.41 (National Institutes of Health, Bethesda, MD, USA). GAPDH was used as a control.

Cell proliferation assay. The proliferation of RPE cells was examined using Cell Counting kit-8 (CCK-8; Sigma-Aldrich) according to the manufacturer's protocol. Briefly, RPE cells were seeded into 96 -well plates at the density of $5 \times 10^{3}$ cells/well with $100 \mu \mathrm{l}$ of complete culture medium (Invitrogen; Thermo Fisher Scientific, Inc.) and cultured for $24 \mathrm{~h}$. Cells were then treated with 1, 10, 25 and $50 \mu \mathrm{M}$ LYTAK 1 for 24, 48 and $72 \mathrm{~h}$. At the end of each treatment period, $10 \mu \mathrm{l}$ CCK-8 solution was added to each well and incubated for $2 \mathrm{~h}$ at $37^{\circ} \mathrm{C}$. The absorbance was determined at $450 \mathrm{~nm}$ with a microplate reader (Model 680; Bio-Rad Laboratories, Inc., Hercules, CA, USA).

Statistical analysis. Data in the current study are expressed as the mean \pm standard deviation. Statistical differences between the means of two groups was analysed using Student's t-test, and between greater than two groups using one-way analysis of variance followed by multiple comparisons performed using a post hoc Bonferroni test in SPSS version 16.0 (SPSS, Inc., Chicago, IL, USA). $\mathrm{P}<0.05$ was considered to indicate a statistically significant difference.

\section{Results}

Expression of TAK1 in TGF- $\beta 1$-induced EMT of RPE cells. The expression of TAK1 in TGF- $\beta 1$-induced EMT of human RPE cells was determined by RT-qPCR. The results indicated that TGF- $\beta 1$ significantly increased TAK1 mRNA expression levels $(\mathrm{P}<0.05$; Fig. 1A). Additionally, the upregulation of 
A

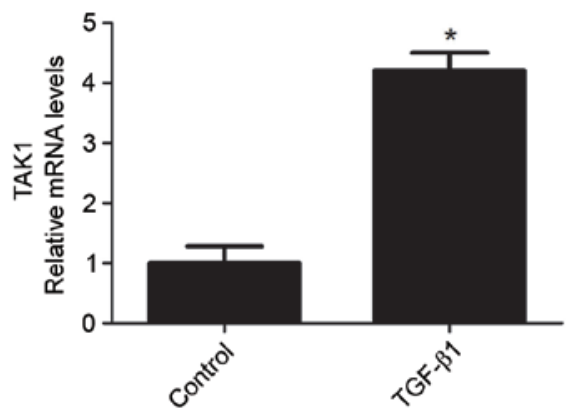

B

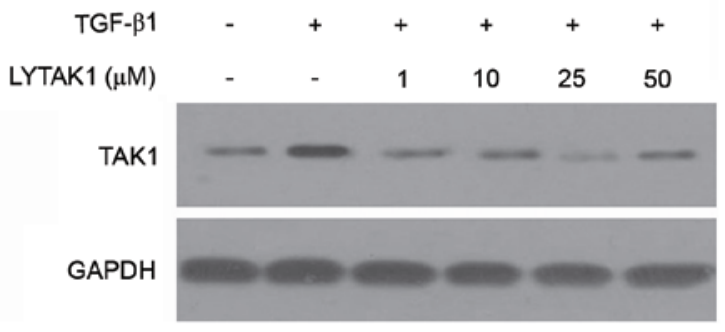

C

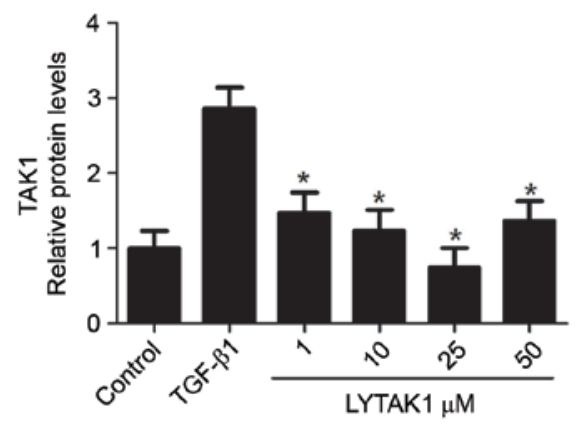

Figure 1. Expression of TAK1 in TGF- $\beta 1$-induced epithelial-mesenchymal transition of RPE cells. (A) RPE cells were cultured in the presence or absence of TGF- $\beta 1$ for $24 \mathrm{~h}$; mRNA expression levels of TAK1 were detected by reverse transcription-quantitative polymerase chain reaction. Data are expressed as the mean \pm standard deviation. ${ }^{*} \mathrm{P}<0.05$ vs. the control group. (B) Protein expression levels of TAK1 in cells cultured in the absence or presence of TGF- $\beta 1$ with LYTAK1 or DMSO were detected by western blotting. (C) Quantification of TAK1 protein levels from three independent experiments. Data are presented as the mean \pm standard deviation." $\mathrm{P}<0.05$ vs. TGF- $\beta 1$ treated with dimethyl sulfoxide group. TGF- $\beta 1$, transforming growth factor $\beta-1$; TAK1, TGF- $\beta 1$-activated kinase; RPE, retinal pigment epithelium; DSMO, dimethyl sulfoxide; GAPDH, glyceraldehyde 3-phosphate dehydrogenase.

TAK1 expression levels induced by TGF- $\beta 1$ were significantly inhibited by LYTAK1 ( $\mathrm{P}<0.05$; Fig. 1B and $\mathrm{C})$. These results suggest that TAK1 is upregulated in TGF- $\beta 1$-induced EMT in RPE cells.

LYTAK1 prevents TGF- $\beta 1$-induced EMT in RPE cells. During EMT, the expression levels of the mesenchymal markers fibronectin and $\alpha$-smooth muscle actin ( $\alpha$-SMA) are upregulated. In order to investigate whether TAK1 inhibition prevents TGF- $\beta 1$-induced EMT in RPE cells, the mRNA and protein levels were determined by RT-qPCR and western blotting respectively. TGF- $\beta 1$ significantly increased the expression of $\alpha$-SMA and fibronectin compared with the control at the mRNA $(\mathrm{P}<0.05$; Fig. $2 \mathrm{~A})$ and protein levels $(\mathrm{P}<0.05$; Fig. $2 \mathrm{~B}$ and $\mathrm{C})$. Notably, LYTAK1 treatment
A

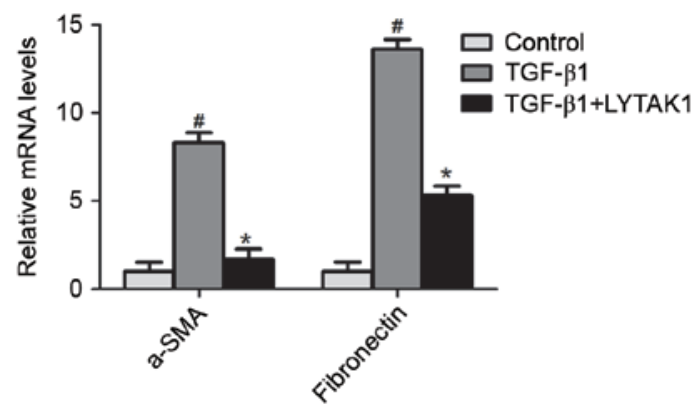

B

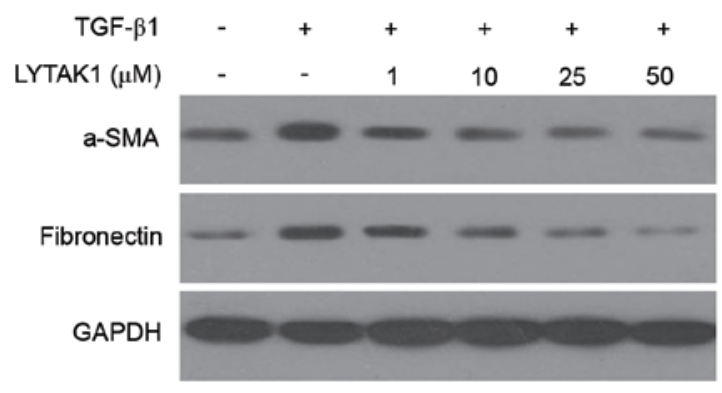

C

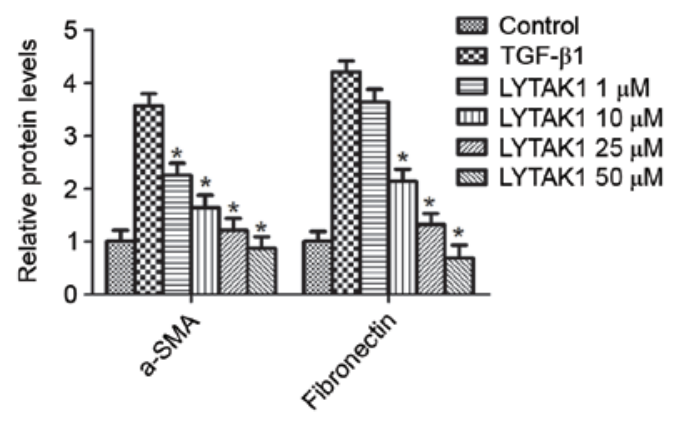

Figure 2. LYTAK1 prevents TGF- $\beta 1$-induced epithelial-mesenchymal transition in RPE cells. RPE cells were cultured in the absence or presence of TGF- $\beta 1$ with LYTAK1 or DMSO for $24 \mathrm{~h}$. (A) mRNA expression levels of $\alpha$-SMA and fibronectin were determined by reverse transcription-quantitative polymerase chain reaction. Data are expressed as the mean \pm standard deviation. ${ }^{\#} \mathrm{P}<0.05$ vs. control; ${ }^{*} \mathrm{P}<0.05$ vs. TGF- $\beta 1$ treated with DMSO group. (B) Protein expression levels of $\alpha$-SMA and fibronectin were detected by western blotting. (C) Quantification of protein levels from three independent experiments. Data are expressed as the mean \pm standard deviation. ${ }^{*} \mathrm{P}<0.05$ vs. TGF- $\beta 1$ treated with DMSO group. $\alpha$-SMA, $\alpha$-smooth muscle actin; TGF- $\beta 1$, transforming growth factor $\beta-1$; RPE, retinal pigment epithelium; DSMO, dimethyl sulfoxide; GAPDH, glyceraldehyde 3-phosphate dehydrogenase.

significantly reduced the upregulation of $\alpha$-SMA and fibronectin induced by TGF- $\beta 1$ in a concentration-dependent manner $(\mathrm{P}<0.05$; Fig. 2$)$. Therefore, these data indicate that the TAK1 inhibitor, LYTAK1 significantly attenuates TGF- $\beta 1$-induced EMT in RPE cells.

LYTAK1 inhibits the proliferation of RPE cells. RPE cell proliferation is important in the progression of PVR. Therefore, the effect of the TAK1 inhibitor, LYTAK1, on the growth of RPE cells was examined. As indicated in Fig. 3, LYTAK1 exhibited significant inhibitory effects on cell growth for 48 and $72 \mathrm{~h}$ in a concentration dependent manner $(\mathrm{P}<0.05)$; however, no effect was observed after $24 \mathrm{~h}$ of treatment. These results indicate that LYTAK1 may successfully inhibit the proliferation of RPE cells. 


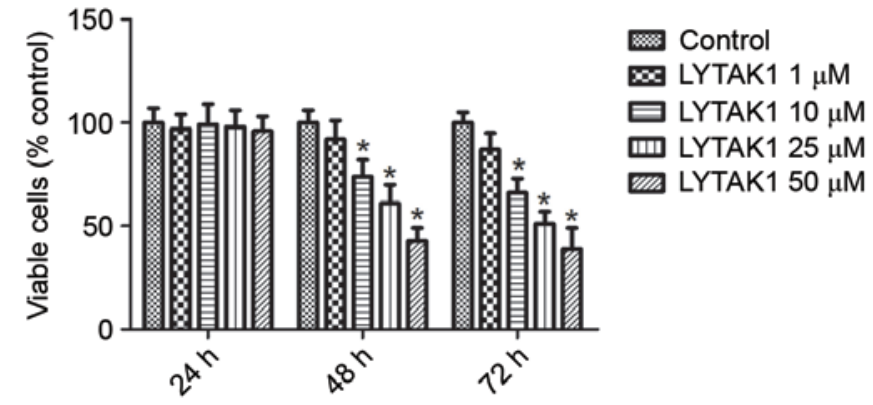

Figure 3. LYTAK1 inhibited the proliferation of RPE cells. RPE cells were treated with LYTAK1 at different concentrations for 24, 48 and $72 \mathrm{~h}$, and then the percentage of viable cells was determined using Cell Counting kit-8. ${ }^{*} \mathrm{P}<0.05$ vs. control. RPE, retinal pigment epithelium.

A

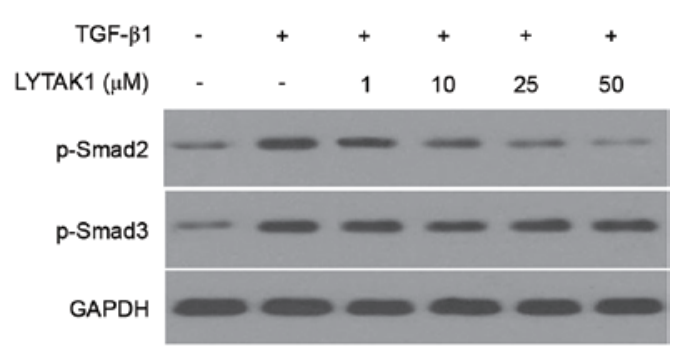

B

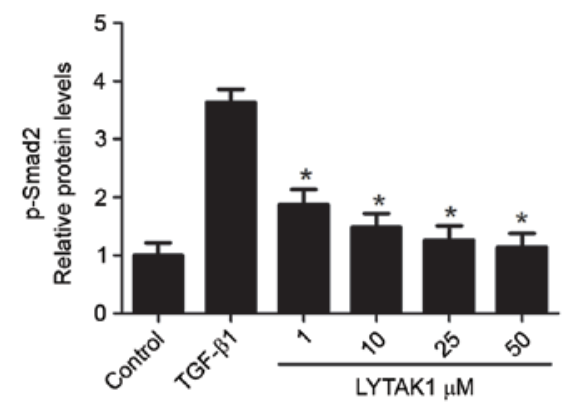

C

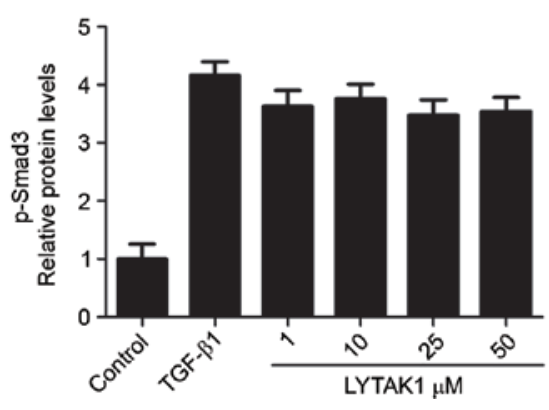

Figure 4. LYTAK1 inhibited the TGF- $\beta 1$ signaling pathway by suppressing the phosphorylation of Smad2. (A) The phosphorylation levels of Smad2 and Smad3 were detected by western blotting 60 min after treatment Quantification of (B) p-Smad2 and (C) p-Smad3 protein levels from three independent experiments. ${ }^{*} \mathrm{P}<0.05$ vs. TGF- $\beta 1$ treated with dimethyl sulfoxide group. TGF- $\beta 1$, transforming growth factor $\beta-1$; $\mathrm{p}-$, phosphorylated; GAPDH, glyceraldehyde 3-phosphate dehydrogenase.

LYTAK1 inhibits the TGF- $\beta 1$ signaling pathway by suppressing the phosphorylation of Smad2. In order to determine the underlying mechanism of the inhibitory effect of LYTAK 1 on TGF- $\beta 1$ signaling, the effect of LYTAK1 on the phosphorylation of Smad2 and Smad3 was investigated. As shown in Fig. 4,
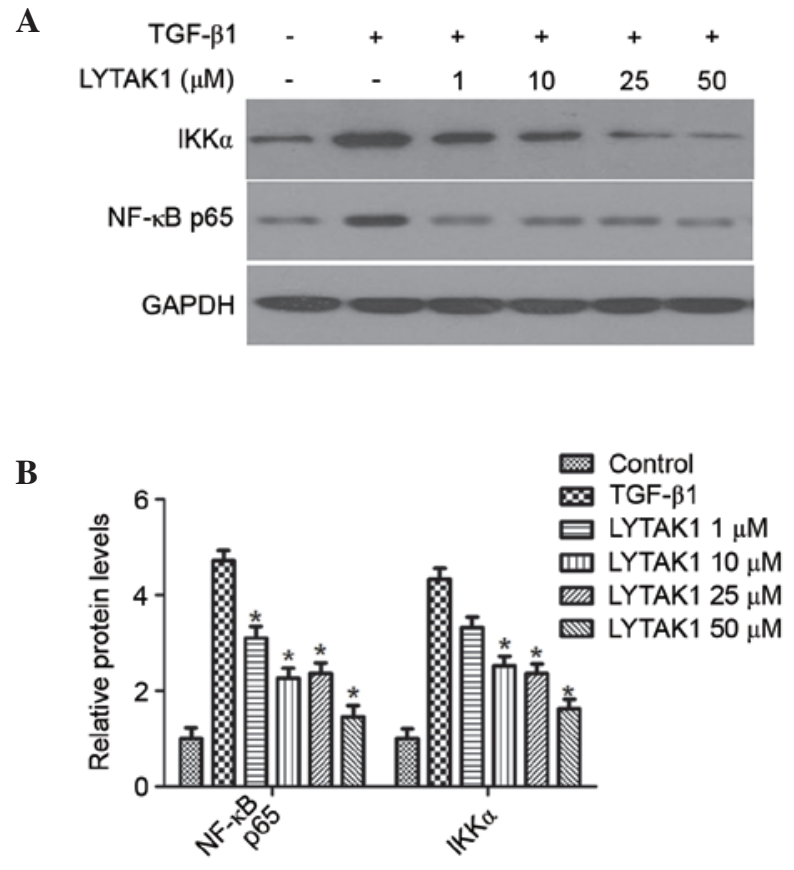

Figure 5. LYTAK1 reduced TGF- $\beta 1$-induced EMT via downregulation of the NF- $\mathrm{KB}$ signaling pathway. (A) Retinal pigment epithelium cells were treated with TGF- $\beta 1$ in the absence or presence of LYTAK1 for $24 \mathrm{~h}$. Levels of phosphorylated NF- $\mathrm{KB}$ p 65 and IKK $\alpha$ were detected by western blotting. (B) Quantification of protein levels from three independent experiments. ${ }^{*} \mathrm{P}<0.05$ vs. the TGF- $\beta 1$-treated group. TGF- $\beta 1$, transforming growth

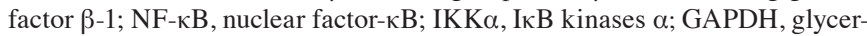
aldehyde 3-phosphate dehydrogenase.

TGF- $\beta 1$ treatment led to the phosphorylation of Smad2 and Smad3 after $60 \mathrm{~min}$. When cells were treated with LYTAK1, the phosphorylation of Smad2 was significantly inhibited in a concentration-dependent manner when compared with the TGF- $\beta 1$ group (Fig. 4B; $\mathrm{P}<0.05$ ). However, no effect on the phosphorylation of Smad3 was observed (Fig. 4C). These results suggest that LYTAK1 suppresses TGF- $\beta 1$ signaling via the phosphorylation of Smad2.

LYTAK1 reduces TGF-ß1-induced EMT via downregulation of the $N F-\kappa B$ pathway. TAK1 is an established upstream kinase required for NF- $\mathrm{kB}$ activation, which is important for cell progression. Therefore, the effects of LYTAK1 on $\mathrm{NF}-\mathrm{kB}$ signaling in RPE cells undergoing TGF- $\beta 1$-induced EMT was investigated. The results demonstrated that TGF- $\beta 1$ treatment alone led to a significant increase of the phosphory-

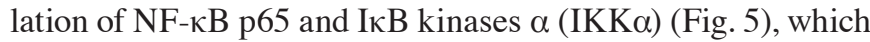
are indicators of NF- $\kappa \mathrm{B}$ activation. LYTAK1 treatment was able to significantly attenuate the TGF- $\beta 1$-induced phosphorylation of NF- $\mathrm{KB}$ p65 and IKK $\alpha$ in a concentration-dependent manner ( $\mathrm{P}<0.05$; Fig. 5B).

\section{Discussion}

Epithelial to mesenchymal transition is an important morphological step, which occurs during embryonic development. This process is also observed in adults during wound healing, tumor progression and organ fibrosis (14). PVR, an ocular fibrotic disease, is a process that entails fibrocellular proliferation in the vitreous cavity (15). The gradual 
contraction of epiretinal membranes leads to a marked distortion of the retinal structure and results in retinal detachment and the loss of vision. RPE cells are the primary cell type involved in the pathogenesis of PVR, which results from EMT, proliferation, and migration of transformed RPE cells to the vitreous $(16,17)$. The importance of EMT in the development of PVR has become evident.

TAK1 has been identified as a central regulator of diverse physiological processes, including development, metabolism, and immune and stress responses, which in turn trigger the activation of the transcription factors $N F-\kappa B$ and activation protein 1 (AP-1) (17). A previous study also described the importance of TAK1 in the progression of cancer cells (18) and it has been demonstrated that TAK1 is overexpressed and/or overactivated in numerous types of cancer $(19,20)$. Inhibition of TAK1 via pharmacological or genetic methods has been indicated to induce apoptosis in cancer cells (21). TAK1 has been identified to contribute to the non-canonical pathway of the TGF- $\beta 1$ response (22). Therefore, TAK1 controls the phosphorylation of downstream proteins, such as $\mathrm{p} 38$. The present study demonstrated that the TAK1 inhibitor, LYTAK1, was able to suppress the proliferation of RPE cells and decrease the expression levels of the mesenchymal markers, fibronectin and $\alpha$-SMA, indicating that TAK1 is involved in the maintenance of the mesenchymal properties of transformed RPE cells.

TGF- $\beta 1$ predominantly acts via the following pathways: i) The canonical Smad-dependent pathway and ii) the non-canonical Smad-independent pathway. The canonical TGF- $\beta 1 /$ Smad signaling transmits a signal via binding to two associated transmembrane type I and type II receptors, which subsequently phosphorylate receptor-regulated Smad proteins-Smad2 and/or Smad3 (23). The effect of LYTAK1 on the activation of Smad2 and Smad3 induced by TGF- $\beta 1$ was examined in the present study. It was determined that LYTAK1 may inhibit the phosphorylation of Smad2 induced by TGF- $\beta 1$; however, it had no effect on the phosphorylation of Smad3 in RPE cells. These results suggest that LYTAK1 may mediate the canonical TGF- $\beta 1 /$ Smad signaling via suppression of the phosphorylation of Smad2.

TGF- $\beta 1$ signaling is vital for the signaling networks, which control EMT. However, it is not limited to the canonical Smad signaling pathway, as non-Smad signaling pathways may also be influenced. TAK1, an MAPK, contributes to the activation of $\mathrm{NF}-\kappa \mathrm{B}$ and AP-1, which may suppress proapoptotic signaling pathways and thus promote resistance to chemotherapeutic drugs (18). A previous study indicated that TAK1, via the $\mathrm{NF}-\kappa \mathrm{B}$ signaling pathway, triggered increased EMT and led to increased invasiveness of tumors (24). In the present study, LYTAK1 was identified to inhibit TGF- $\beta 1$-induced EMT via the $\mathrm{NF}-\kappa \mathrm{B}$ pathway.

In conclusion, the current study demonstrated that the inhibition of TAK1 activity with LYTAK1 treatment leads to the reduction of cell proliferation and TGF- $\beta 1$-induced EMT in human RPE cells. The mechanism underlying EMT suppression by LYTAK1 involved the inactivation of the canonical Smad signaling pathway. In addition, the NF- $\kappa \mathrm{B}$ signaling pathway may also contribute to the reduction in EMT. The findings of the present study establish a framework for further research on the importance of EMT in RPE in a number of proliferative vitreoretinopathies characterized by EMT.

\section{Acknowledgements}

The present study was supported by the Department of Technology Application and Development of Yunnan Province (grant no. 2014RA070).

\section{References}

1. Bharti K, Nguyen MT, Skuntz S, Bertuzzi S and Arnheiter H: The other pigment cell: Specification and development of the pigmented epithelium of the vertebrate eye. Pigment Cell Res 19: 380-394, 2006.

2. Strauss O: The retinal pigment epithelium in visual function. Physiol Rev 85: 845-881, 2005.

3. Takahashi E, Nagano O, Ishimoto T, Yae T, Suzuki Y, Shinoda $\mathrm{T}$, Nakamura $\mathrm{S}$, Niwa $\mathrm{S}$, Ikeda $\mathrm{S}$, Koga $\mathrm{H}$, et al: Tumor necrosis factor-alpha regulates transforming growth factor-beta-dependent epithelial-mesenchymal transition by promoting hyaluronan-CD44-moesin interaction. J Biol Chem 285: 4060-4073, 2010.

4. Garweg JG, Tappeiner C and Halberstadt M: Pathophysiology of proliferative vitreoretinopathy in retinal detachment. Surv Ophthalmol 58: 321-329, 2013.

5. Lamouille $\mathrm{S}$ and Derynck R: Cell size and invasion in TGF-beta-induced epithelial to mesenchymal transition is regulated by activation of the mTOR pathway. J Cell Biol 178: 437-451, 2007.

6. Saika S: TGFbeta pathobiology in the eye. Lab Invest 86: 106-115, 2006.

7. Desmoulière A, Geinoz A, Gabbiani $F$ and Gabbiani G: Transforming growth factor-beta 1 induces alpha-smooth muscle actin expression in granulation tissue myofibroblasts and in quiescent and growing cultured fibroblasts. J Cell Biol 122: 103-111, 1993.

8. Yoon YS, Lee JH, Hwang SC, Choi KS and Yoon G: TGF beta1 induces prolonged mitochondrial ROS generation through decreased complex IV activity with senescent arrest in Mv1Lu cells. Oncogene 24: 1895-1903, 2005.

9. Mu Y, Gudey SK and Landström M: Non-Smad signaling pathways. Cell Tissue Res 347: 11-20, 2012.

10. Kim SI, Kwak JH, Na HJ, Kim JK, Ding Y and Choi ME: Transforming growth factor-beta (TGF-beta1) activates TAK1 via TAB1-mediated autophosphorylation, independent of TGF-beta receptor kinase activity in mesangial cells. J Biol Chem 284: 22285-22296, 2009.

11. Sato S, Sanjo H, Takeda K, Ninomiya-Tsuji J, Yamamoto M, Kawai T, Matsumoto K, Takeuchi O and Akira S: Essential function for the kinase TAK1 in innate and adaptive immune responses. Nat Immunol 6: 1087-1095, 2005.

12. Hanada M, Ninomiya-Tsuji J, Komaki K, Ohnishi M, Katsura K, Kanamaru R, Matsumoto K and Tamura S: Regulation of the TAK1 signaling pathway by protein phosphatase 2C. J Biol Chem 276: 5753-5759, 2001.

13. Livak KJ and Schmittgen TD: Analysis of relative gene expression data using real-time quantitative PCR and the 2(-Delta Delta C(T)) Method. Methods 25: 402-408, 2001.

14. Kalluri R: EMT: When epithelial cells decide to become mesenchymal-like cells. J Clin Invest 119: 1417-1419, 2009.

15. García S, López E and López-Colomé AM: Glutamate accelerates RPE cell proliferation through ERK1/2 activation via distinct receptor-specific mechanisms. J Cell Biochem 104: 377-390, 2008.

16. Palma-Nicolás JP, López E and López-Colomé AM: Thrombin stimulates RPE cell motility by PKC-zeta-and NF-kappa $\mathrm{B}$-dependent gene expression of MCP-1 and CINC-1/GRO chemokines. J Cell Biochem 110: 948-967, 2010.

17. Adhikari A, Xu M and Chen ZJ: Ubiquitin-mediated activation of TAK1 and IKK. Oncogene 26: 3214-3226, 2007.

18. Sakurai H: Targeting of TAK1 in inflammatory disorders and cancer. Trends Pharmacol Sci 33: 522-530, 2012.

19. Melisi D, Xia Q, Paradiso G, Ling J, Moccia T, Carbone C, Budillon A, Abbruzzese JL and Chiao PJ: Modulation of pancreatic cancer chemoresistance by inhibition of TAK1. J Natl Cancer Inst 103: 1190-1204, 2011.

20. Singh A, Sweeney MF, Yu M, Burger A, Greninger P, Benes C, Haber DA and Settleman J: TAK1 inhibition promotes apoptosis in KRAS-dependent colon cancers. Cell 148: 639-650, 2012. 
21. Neil JR, Tian M and Schiemann WP: X-linked inhibitor of apoptosis protein and its E3 gene ligase activity promote transforming growth factor-beta-mediated nuclear factor-kappaB activation during breast cancer progression. J Biol Chem 284: 21209-21217, 2009.

22. Landström M: The TAK1-TRAF6 signalling pathway. Int J Biochem Cell Biol 42: 585-589, 2010.
23. Akhurst RJ and Hata A: Targeting the TGF $\beta$ signalling pathway in disease. Nat Rev Drug Discov 11: 790-811, 2012.

24. Huber MA, Azoitei N, Baumann B, Grünert S, Sommer A, Pehamberger H, Kraut N, Beug H and Wirth T: NF-карраB is essential for epithelial-mesenchymal transition and metastasis in a model of breast cancer progression. J Clin Invest 114: 569-581, 2004. 